\title{
Consent and Coercion: Examining Unwanted Sex Among Married Young Women in India
}

By K.G. Santhya, Nicole Haberland, F. Ram, R.K. Sinha and S.K. Mohanty

K.G. Santhya is senior program officer, Population Council, New Delhi. Nicole Haberland is program associate, Population

Council, New York.

F. Ram is professor,

R.K. Sinha is reader and S.K. Mohanty is lecturer-all at the International Institute for Population Sciences, Mumbai.
CONTEXT: Although there is a growing body of research examining the issue of nonconsensual sex among adolescents, few studies have looked at coerced sex within marriage in settings where early marriage is common, or at sex that may not be perceived as forced, but that is unwanted.

METHODS: A cross-sectional study, using both survey research and in-depth interviews, was conducted among 1,664 married young women in Gujarat and West Bengal, India. Descriptive data and multinomial logistic regression were used to identify the prevalence and risk factors for occasional and frequent unwanted sex. Qualitative data were analyzed to examine the context in which unwanted sex takes place.

RESULTS: Twelve percent of married young women experienced unwanted sex frequently; $32 \%$ experienced it occasionally. The risk of experiencing unwanted sex was lower among women who knew their husband fairly well at the time of marriage, regularly received support from their husband in conflicts with other family members or lived in economically better-off households. Frequent unwanted sex was associated with not yet having had a child or having become pregnant, with lower education and with agreeing with norms that justify wife beating.

CONCLUSION: For married young women, sex is not always consensual or wanted. Further research is required to determine the effects of unwanted sex on sexual and reproductive health outcomes and to help programs develop the best strategies for dealing with coerced sex within marriage.

International Family Planning Perspectives, 2007, 33(3):124-132
A growing body of research explores the nonconsensual sexual experiences of young people in developing countries. A recent review of evidence suggests that significant minorities of young people-perhaps as many as one in 10 young men and one in five young women-have experienced nonconsensual sex. ${ }^{1}$ In addition, between 2\% and 33\% of ever-partnered young women in Latin America and the Caribbean, ${ }^{2}$ and between $3 \%$ and 33\% of ever-married or -partnered young women in Asia have experienced coerced sex within a formal union or marriage. ${ }^{3-6}$ According to data from a multicountry study conducted by the World Health Organization, between $4 \%$ and $57 \%$ of ever-partnered 15-19-year-old women had ever experienced sexual violence by an intimate partner, and 3-47\% had experienced such violence in the 12 months preceding the study. ${ }^{7}$ Indeed, these findings suggest that married adolescent girls and young women constitute a group with an elevated risk of coerced sex, compared with older women and sexually active unmarried women. 2,3,7,8 Moreover, adolescent girls and young women who have experienced sexual coercion are more likely to experience a range of negative sexual and reproductive health outcomes, including symptoms of genital tract infection, ${ }^{8,9}$ STIs, ${ }^{10,11}$ unintended pregnancy ${ }^{9,10}$ and nonuse or inconsistent use of condoms. ${ }^{9,12}$

Nonconsensual sex, sexual violence and sexual coercion have been defined and measured in various ways by researchers; these terms have often been used interchange- ably. Although there is a general agreement that nonconsensual sexual experiences include a range of behaviors, including unwanted touch, sex that may not be perceived as forced but is nonetheless unwanted, and coercion into sex through threats and intimidation, as well as rape, ${ }^{1,13,14}$ most studies have looked primarily at forced sex. It is quite likely that other forms of sexual coercion will not be captured by questions using this wording. As Jejeebhoy and Bott note, young people who submit under pressure to a partner's demands for sex as an expression of commitment may not respond in the affirmative to a general question on "forced

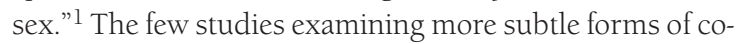
ercion have shown that respondents, given the opportunity, report sexual experiences that they were not forced into, but did not want. ${ }^{15,16}$ These studies indicate a considerably higher proportion of nonconsensual sexual experiences than do studies with questions about forced sex alone. Clearly, studies looking at nonconsensual sex among young people need to include a broad range of coerced experiences to fully explore the continuum of coercion.

The few studies that have looked at factors underlying the nonconsensual sexual experiences of young women suggest links to characteristics such as young age, low educational attainment, young age at sexual initiation, nonresidence with parents, previous experience of coerced sex and having multiple partners. ${ }^{8,17-20}$ Evidence extrapolated primarily from qualitative studies suggests that patri- 
archal norms, power imbalances and women's inability to negotiate sexual matters; lack of awareness of rights and opportunities for recourse; and lack of supportive environments may increase young women's risk of nonconsensual sexual experiences. ${ }^{1}$ Much of this current evidence comes from studies that explored coerced sexual experiences among young women overall; very few have specifically looked at factors underlying sexual coercion within marriage. Further research is needed to gain a better understanding of the prevalence, forms and context of forced sexual relations among married young women; to identify factors that may heighten young women's vulnerability to such experiences within marriage; and to suggest ways to address nonconsensual sexual relations.

In the current study, we examine the extent of unwanted sexual experiences among married young women in rural settings in India. Sexual activity among adolescent girls and young women in India takes place for the most part within the context of marriage-as many as $25 \%$ of adolescent girls aged 15-19 are married and presumably sexually active, while fewer than $10 \%$ of unmarried young women are reported to be sexually experienced. ${ }^{21,22}$ Marriage does not inherently make sex safe, voluntary or pleasurable. Indeed, the marriages of $10-15 \%$ of adolescent brides are consummated by force. ${ }^{6,23-28}$ However, evidence remains sparse on the patterns and dynamics of sexual coercion within marriage. Most of the evidence on nonconsensual sexual experiences within marriage currently available in India comes from unrepresentative, small-scale studies, most of which were qualitative. With data from a cross-sectional study that used both quantitative and qualitative methods, this article explores the nature and context of unwanted sex within marriage and the factors that are associated with such experiences.

\section{METHODS}

\section{Study Setting}

The study was conducted in two rural settings in IndiaVadodara Block, in the state of Gujarat, and Diamond Harbour Block, in the state of West Bengal. Gujarat, situated on the west coast of India, is home to 50.7 million people. ${ }^{29}$ West Bengal is located in the eastern part of the country and has 80.2 million inhabitants. The two states account for $5 \%$ and $8 \%$, respectively, of India's population. Gujarat is more urbanized than West Bengal (37\% vs. $28 \%$ of the population). As elsewhere in India, the sex ratio is skewed in favor of males in both states, but the imbalance is more dramatic in Gujarat than in West Bengal (921 females per 1,000 males vs. 934 females per 1,000 males, respectively).

According to 2001 census data, many adolescent girls (15-19-year-olds) in these two states are illiterate-23\% in Gujarat and 25\% in West Bengal (27\% nationally). ${ }^{29}$ A substantial proportion are already married-18\% in Gujarat and 29\% in West Bengal (25\% nationally). ${ }^{21}$ In rural areas, the proportion of ever-married adolescent girls is $21 \%$ in Gujarat and 34\% in West Bengal (29\% nationally). Nearly one-quarter (23\%) of married adolescent girls in Gujarat and more than two-fifths (42\%) in West Bengal are already mothers (30\% nationally).

\section{Data}

Data presented in this article were drawn from a crosssectional study comprising survey research conducted from August 2002 to February 2003 and in-depth interviews conducted from August through October 2003. This study was undertaken as a baseline assessment prior to launching a pilot project that aimed to improve married young women's reproductive health knowledge and practices, and to increase their ability to act in their own interests. The intervention villages (13 in Gujarat and 12 in West Bengal) were purposively selected in consultation with the nongovernmental organizations that implemented the intervention activities. Villages that had social and demographic characteristics comparable to those of the intervention villages were selected as controls (11 in Gujarat and 13 in West Bengal). In total, the study was conducted in 49 villages, with a total population of about 88,000 . The population to be covered at baseline and during the intervention phase was determined by calculating the sample size necessary to assess the effects of the intervention on such indicators as young women's nonfamilial connections; autonomy; knowledge of key reproductive health issues; reproductive health practices, including using contraceptives; obtaining a minimum of antenatal care; seeking skilled attendance for delivery and seeking postpartum checkups.

The respondents who participated in the baseline study included young women who had married during the two years preceding the survey, young women who were pregnant for the first time and first-time mothers who were up to 18 months postpartum. The respondents were identified through a household listing exercise. This exercise entailed listing, for each household in the study villages, all usual residents and any visitor who had stayed in the household the previous night. For each listed person, information was collected on age, sex, marital status, year and month of marriage, and for each woman, whether she had ever given birth and the number of births she had had. All eligible women identified at the time of the household listing were invited to participate in the survey. A total of 2,862 women were identified and of these, 2,115 women (1,079 in Gujarat and 1,036 women in West Bengal) were successfully interviewed. The refusal rate was lower than $1 \%$ in each site, but we were unable to interview $25 \%$ of the eligible respondents because they were not available. This was due primarily to customs in the study villages-married young women move frequently between their natal and marital homes during the early days of marriage, and they often return to their natal home for their first birth.

\section{Survey}

A structured questionnaire was used to explore a wide range of issues, including young women's transition to marriage; work experience; access to and control over resources; mobility; social connections; spousal communication and sup- 
port; experience of physical abuse and unwanted sex; and reproductive health knowledge and practices. The draft questionnaire was pretested with 50 eligible women in two villages that were not part of the study; necessary modifications were made to ensure the reliability of the measures. Trained female interviewers administered the questionnaire at the respondent's home and ensured that the interviews were conducted in private.

For the current study, we explored the issue of unwanted sexual experiences only among the subsample of respondents who usually told their husbands when they did not want to have sex. These young women made up $79 \%$ of the total sample; the final sample size was 1,664 women. Although we did not base our sample size calculation on estimates of prevalence of unwanted sex within marriage, postsurvey analysis suggests that the sample was larger than what was required to yield an estimate with two percentage-point precision and 95\% confidence. Multinomial logistic regression was used to identify variables independently associated with frequent and occasional unwanted sex-that is, how women who experience unwanted sex frequently and those who experience it occasionally differ from those who do not experience it.

\section{In-Depth Interviews}

In addition, we conducted in-depth interviews with 69 women (30 in Gujarat and 39 in West Bengal) who participated in the survey to gather additional insights about young women's transition to marriage, partner relationships, exercise of sexual rights and level of autonomy in reproductive health matters. At each site, respondents for the interviews were identified on the basis of a preliminary analysis of the survey data on young women's role in household decisions, their mobility and their level of partner support. We interviewed three to four women categorized as having low, medium and high scores on these indicators* from each of the target groups: those who were recently married, those who were pregnant for the first time and first-time mothers. The interviews were conducted at respondents' homes by investigators who had participated in the survey and were experienced in gathering qualitative data. The interviewers transcribed each interview in the local language; the transcripts were later translated into English. A coding scheme was developed using the broad themes listed in the interview guide and those identified through a preliminary reading of a subset of the transcripts. Then, the transcripts were coded in ATLAS.ti; blocks of text related to specific themes were analyzed to capture typical patterns and exceptions.

\section{Variables}

Respondents were asked whether they usually told their husbands when sex was not wanted and whether their husbands "always," "sometimes," "rarely" or "never" respect-

*Young women who scored low on at least two indicators were classified as low, those who scored medium on at least two indicators were classified as medium and those who scored high on at least two indicators were classified as high. ed their wishes. A variable with three categories reflecting different degrees of unwanted sexual experience was constructed: "frequent unwanted sex," the husband rarely or never respected the wife's wishes when she said no to sex; "occasional unwanted sex," the husband sometimes respected the wife's wishes; and "no unwanted sex," the husband always respected the wife's wishes. Frequent unwanted sex was coded as 2 , occasional unwanted sex was coded as 1 and no unwanted sex was coded as 0 .

To identify factors associated with unwanted sex, we considered a variety of individual, relationship, household and contextual factors. At the individual level, such background characteristics as age (in years), years of schooling completed and current work status (whether the respondent was engaged in paid or unpaid work in the six months preceding the survey, coded as 0 for not currently working and 1 for working) were included in the analysis. A variable indicating the current life stage of the respondent-newly married (coded as 0 ), in her first pregnancy (coded as 1) or a firsttime mother (coded as 2)-was also included in the model.

Power imbalances, the inability to negotiate on sexual matters and patriarchal norms that justify sexual violence have been hypothesized as increasing young women's risk of nonconsensual sexual experiences. ${ }^{1}$ Our model included a number of variables reflecting young women's attitudes and autonomy, including their gender role attitudes, their attitudes toward gender-based violence and their role in household decision making.

To capture young women's gender role attitudes, respondents were asked whether they agreed or disagreed with the following statements: a husband should help with the children and household chores; a woman should be allowed to work for pay; girls should be allowed to decide when and whom they want to marry; a husband should decide how household money is spent; when money is scarce and a family cannot send all children to school, boys should be sent before girls; during a woman's labor and childbirth, there is no role a husband can play; and if a woman's opinion differs from her husband's opinion, she must accept his. The respondent was assigned a score of 1 for each egalitarian statement she agreed with; for nonegalitarian statements, a score of 1 was assigned if she disagreed. An index with potential scores ranging from 0 to 7 , where higher scores imply more egalitarian attitudes, was constructed.

Young women's attitudes toward gender-based violence were measured by an index based on their responses to eight statements. Respondents were asked whether they agreed or disagreed that a husband is justified in beating his wife for the following reasons: if her natal family does not give expected money, jewelry or other items; if she refuses to have sexual relations with her husband; if he does not like the food she cooks; if she disobeys elders in the household; if she uses a contraceptive without her husband's permission; if she disobeys her husband; if she neglects the house or children; and if he suspects her of being unfaithful. Potential scores ranged from 0 to 8; with higher scores implying strong acceptance of men's right to beat their wives under certain circumstances. 
Also included was an index (potential scores, 0-12) reflecting young women's role in decisions related to various household purchases. The respondents were asked whether they had any role in decisions related to purchasing the following items: food, small gifts, jewelry, clothes, livestock or any other expensive items. A score of 0 was assigned if the respondent had no role, 1 if she had some say and 2 if she had final say. A higher score indicates a larger role in decision making related to household purchases.

At the relationship level, we included variables indicating the nature of the relationship, including how often the spouses spent time together $(0=$ frequently, $1=$ sometimes, $2=$ rarely or never and $3=$ only at night) and the extent to which husbands supported their wife when she was in conflict with a family member ( $0=$ always, $1=$ sometimes and $2=$ rarely or never). A variable reflecting young women's transition to marriage and sexual life-indicated by familiarity with their husband at the time of marriage-was also included in the model; responses were coded as 0 if the wife was not familiar with her husband before marriage, 1 if she was somewhat familiar and 2 if she was fairly or very familiar with her husband before marriage. Also included in the analysis were young women's characteristics relative to those of their husbands, such as the differences between spouses in age $(0=$ less than or equal to two years, $1=$ three to five years and $2=$ six or more years) and level of education ( $0=$ husband more educated than wife, 1 =husband and wife similarly educated and $2=$ wife more educated than husband).

At the household level, variables such as family type $(0=$ nuclear, $1=$ extended $)$ and religion $(0=$ Hindu and $1=$ Muslim) were included. To measure the standard of living of the marital family, an additive index was created based on quality of materials used to construct the respondent's house, ownership of agricultural land and livestock and ownership of household durables (pressure cooker, electric fan, bicycle, radio, sewing machine, telephone, refrigerator, television, motorcycle and car or tractor). The scores assigned to individual items ranged from 0 to 4 , and were similar to those used in the National Family Health Survey2. The value of the index ranged from 0 to 34; scores from 0 to 4 were classified as low, 5-14 as medium and 15 or above as high. To account for contextual differences between study sites, a variable denoting the study states was included $(0=$ Gujarat, $1=$ West Bengal).

\section{RESULTS}

\section{Saying No When Sex Is Unwanted}

In all, almost four in five young women reported usually saying no to their husband when they did not want to have sex (not shown). There were significant differences between women who articulated their preference when sex was unwanted and those who did not (Table 1). Compared with women who articulated their preference, those who did not were more likely to be recently married and less likely to be first-time mothers; similar proportions of those who told and those who did not were pregnant for the first time. Those who did not tell their husband when sex was unwanted tend-

\begin{tabular}{|c|c|c|}
\hline Characteristic & $\begin{array}{l}\text { Women who } \\
\text { told their } \\
\text { husband } \\
(\mathrm{N}=1,664)\end{array}$ & $\begin{array}{l}\text { Women who } \\
\text { did not tell their } \\
\text { husband } \\
(\mathrm{N}=442)\end{array}$ \\
\hline \multicolumn{3}{|l|}{ Age } \\
\hline$\leq 17$ & 19.7 & 22.2 \\
\hline $18-19$ & 37.0 & 38.7 \\
\hline$\geq 20$ & 43.3 & 39.1 \\
\hline \multicolumn{3}{|l|}{ Current life stage ${ }^{* * *}$} \\
\hline Recently married & 31.9 & 43.7 \\
\hline Pregnant for the first time & 12.7 & 11.8 \\
\hline First-time mother & 55.4 & 44.6 \\
\hline \multicolumn{3}{|l|}{ Years of schooling* } \\
\hline 0 & 16.7 & 18.4 \\
\hline $1-5$ & 31.5 & 37.4 \\
\hline $6-9$ & 33.5 & 31.1 \\
\hline$\geq 10$ & 18.3 & 13.2 \\
\hline \multicolumn{3}{|l|}{ Current work status } \\
\hline Working & 11.5 & 13.6 \\
\hline Not working & 88.5 & 86.4 \\
\hline \multicolumn{3}{|l|}{ Family type ${ }^{* * *}$} \\
\hline Nuclear & 20.4 & 12.5 \\
\hline Extended & 79.6 & 87.5 \\
\hline \multicolumn{3}{|l|}{ Religion*** } \\
\hline Hindu & 70.6 & 82.1 \\
\hline Muslim & 29.4 & 17.9 \\
\hline \multicolumn{3}{|l|}{ Standard of living* } \\
\hline Low & 27.8 & 23.0 \\
\hline Medium & 51.8 & 58.9 \\
\hline High & 20.3 & 18.2 \\
\hline Total & 100.0 & 100.0 \\
\hline \multicolumn{3}{|c|}{$\begin{array}{l}\text { *Distribution for women who told their husband when sex was unwanted is } \\
\text { significantly different from the distribution for those who did not at } p \leq .05 \text {. } \\
\text { ***Distribution for women who told their husband when sex was unwanted is } \\
\text { significantly different from the distribution for those who did not at } p \leq .001 \text {. } \\
\text { Note: The standard of living index was based on housing materials and own- } \\
\text { ership of agricultural land, livestock and household durables (pressure cooker, } \\
\text { electric fan, bicycle, radio, sewing machine, telephone, refrigerator, television, } \\
\text { motorcycle, and car or tractor). Scores assigned for owning these assets ranged } \\
\text { from } 1 \text { to } 4 \text {; index score ranged from } 0-34 \text {. Scores of } 0-4 \text { were classified as low, } \\
5-14 \text { as medium and } \geq 15 \text { as high. }\end{array}$} \\
\hline
\end{tabular}

ed to have fewer years of schooling than those who did, and were more likely to live in an extended family, to be Hindu and to have a lower standard of living.

Seven in 10 young women in Gujarat, compared with nine in 10 in West Bengal, reported saying no to their husband when they did not want to have sex (not shown). In the in-depth interviews, the circumstances in which women typically expressed their desire not to have sex also varied between the two sites. In Gujarat, women expressed their desire not to have sex in circumstances that were culturally condoned (for example, during their menstrual period) or that were normally accepted, such as when the women were tired or feeling sick. Of the 30 women interviewed in Gujarat, 15 cited these reasons, while only seven reported that they said no without giving a physical reason.

"If I am tired, then I tell him."-First-time mother 
"I say no for five, six, seven days after my period starts. At that time only."-Recently married woman

In West Bengal, however, most of the young women reported saying no not only during culturally or normally accepted circumstances, but also whenever they did not feel like having sex. Of the 39 women interviewed, 23 cited "not feeling like having sex" as one of the circumstances in which they denied their husband's sexual demands:

"When I have my period, when I don't feel like having sex and when I feel ill, I say no to him."-Recently married woman

"Whenever I don't feel like having sex, I say no to my husband."-Woman in first pregnancy

\section{Experience of Unwanted Sex}

Among the young women who told their husband when they did not want to have sex, a substantial proportion experienced sex that was unwanted and against their will. These experiences occurred with varying frequency, and with differing degrees of coercion. Of the 1,664 women who reported that they indicated when sex was unwanted, $12 \%$ had experienced unwanted sex frequently and $32 \%$ had experienced it occasionally (not shown). In short, as many as 44\% had experienced frequent or occasional sex against their will.

In the in-depth interviews, 62 out of the 69 women had said no when they did not want sex; 25 of these women reported unwanted sexual experiences. When they discussed how often their husband forced them to have sex, the women expressed varying ideas about what constitutes "rare" or "frequent" forced sex.

"My husband sometimes listens to me when I say no to him for sex and sometimes he doesn't listen. Very rare, once or twice in a month, he does sex forcefully."-Recently married woman, West Bengal

"Not always, but rarely, once every four to five months he does that [forces me to have sex]."-Woman in first pregnancy, West Bengal

"He forces me often for sex. We have sex three to four days a week. In one month, he has coerced sex four to five days. I do not feel like having sex, it becomes painful, but he does not stop."-First-time mother, West Bengal

The women discussed circumstances in which they had sex when they did not wish to, without expressing their feelings to their husband for fear of abandonment or quarrel, and in some cases, because of affection.

"I don't like it....If I tell, then he won't listen. I feel that if I don't allow my husband to touch me, he may leave me. That's why I allow him."-Woman in first pregnancy, Gujarat

"[I do not say no to my husband's sexual demands.] What will I get after giving pain to his heart? If he likes it, then let him be happy and it does not matter even if I am not willing for it-if he is happy, then I am also happy."-First-time mother, Gujarat

"Sometimes my husband forces me to have sex, which I don't like. Once I was feeling sick; I had burning sensation while urinating and was feeling giddy. I told him that I didn't feel like having sex at that time, but he didn't lis- ten to me and he forcefully did it. Sometimes he will not listen to any of my problems. If I try to resist him, he will ask me whom should he go to instead and he will get angry. Then I just accept it."-First-time mother, West Bengal

Of the 25 women in the two sites who had experienced unwanted sex, 13 expressed passive or resigned acceptance of the situation.

"He does not force me during my menstruation. When I don't feel good or don't feel like having sex, I say no to him. But those times, he doesn't listen to me. My husband comes home twice every month and if I say no, he does not listen to me. I accept whatever he says. I don't get angry and I never try to make him understand."-First-time mother, West Bengal

"But he does not want to listen to me. He threatens me that he would not come to me anymore. Truly speaking, I love him very much and I feel very bad whenever he is not here. So, when he threatens me, I allow him to have sex, as I am scared that he will not come to me anymore."-Recently married woman, West Bengal

"I feel bad [when he forces me]. But I feel bad also to refuse him sex when he desires; so I allow him to have sex." -Recently married woman, West Bengal

\section{Unwanted Sex and Other Forms of Violence}

Of the women who had experienced unwanted sex, 15\% had also been subjected to physical harassment during the year preceding the survey; of those who did not report any unwanted sexual experiences, $6 \%$ had been subjected to such harassment (not shown). It is not clear from the survey data whether the reported physical abuse was unrelated to or a consequence of young women's articulation of their preference not to have sex. For example, equal proportions of women who did and women who did not say no to their husband's demands for sex reported physical harassment ( $10 \%$ of those who said no and 9\% of those who did not; not shown). However, among those who did express their wishes, there was a higher prevalence of physical abuse among women whose will was frequently ignored (24\%) than among those whose will was occasionally ignored (12\%; not shown). In the in-depth interviews, 13 of the 25 women who had experienced forced sex had also been subjected to physical and emotional harassment, including beating and threats of leaving.

"If I say no at night, he will do it in the morning, I can't say no anytime. He will not say anything at night, he goes to sleep turning his back. But, when he asks for something in the morning and I say no, he beats me."-Woman in first pregnancy, Gujarat

"If he is interested, then I have to have sex. [If I don't allow him,] he quarrels with me."-First-time mother, Gujarat

"Sometimes when I don't feel like having sex and when I feel sick, I say no to him. But he does not listen to me. He forcefully has sex with me. [For example,] one day, I did not feel like having sex. I was sick. He asked me but I said no.... As a result, he became angry. Then he did not talk with me, he told me that he would go to Murshidabad without 
me. The next day he didn't come home."-First-time mother, West Bengal

"He says, 'I don't stay here most of the time and if you don't allow me to have sex with you, why do I come here?' He comes here after one to two weeks and stays here for two to three days. Those days, we have sex during the daytime as well as night. He says...'Whenever I want to have sex, you be ready for that...."'-First-time mother, West Bengal

\section{Correlates of Unwanted Sexual Experiences}

According to a multinomial logistic regression analysis in which women who had not experienced unwanted sex formed the base category, being familiar with one's husband at the time of marriage, having a supportive husband and having a high standard of living in the household were inversely associated with the risk of experiencing both occasional and frequent unwanted sex (Table 2). Women who reported that they had been fairly or very familiar with their husband at the time of marriage were significantly less likely to have experienced occasional or frequent unwanted sex (relative risk ratios, 0.7 and 0.4 , respectively) than were women who had not been at all familiar with their husband. Likewise, women whose husband always supported them in the event of conflict with a family member were only about two-thirds as likely to experience occasional unwanted sex (0.7) and half as likely to experience frequent unwanted sex (0.5) as women whose husband never supported them. Also, women who were living in a household with a high standard of living were at lower risk for occasional unwanted sex (0.6) and lower risk for frequent unwanted sex (0.5) than were women living in households with a low standard of living.

Some characteristics were associated only with frequent unwanted sex. Women in their first pregnancy and those who had recently had their first child were about half as likely as recently married women to be forced into sex frequently (relative risk ratios, 0.5 each). Education was also protective: The risk of experiencing frequent unwanted sex was reduced by $11 \%$ for each year of schooling a woman had successfully completed. In contrast, women who strongly agreed that a husband is justified in beating his wife under certain circumstances were at greater risk of experiencing frequent unwanted sex than women who did not agree (1.2). Also, women who lived in Muslim households were more than twice as likely to experience frequent unwanted sex as those who lived in Hindu households (2.4).

Two factors were associated only with occasional unwanted sex. Women who were currently working were significantly more likely to have experienced occasional unwanted sex than were those who did not work (relative risk ratio, 1.7). In addition, women from West Bengal were more than twice as likely to have experienced occasional unwanted sex as were those from Gujarat (2.4).

\section{DISCUSSION}

Our findings clearly indicate that, for married young women, sex is not always consensual or wanted. Indeed, depending on the level of unwanted sexual experience considered,
TABLE 2. Relative risk ratios for experiencing occasional and frequent unwanted sex from multinational logistic regression among married young women in India who told their husband when they did not want to have sex

Characteristic Occasional Frequent

$\begin{array}{lll}\text { unwanted } & \text { unwanted } \\ \text { sex } & \text { sex }\end{array}$

\section{Individual}

Current age

Current life stage

Recently married (ref)

Pregnant for the first time

First-time mother

Yrs. of schooling

Current work status

Not working (ref)

Working

Index of gender role attitudes

Index of attitudes toward

gender-based violence

Decision-making index

sex

sex

\section{Relationship}

Familiar with husband at marriage

Not at all (ref)

Somewhat

Fairly/very

Spend time together

Frequently (ref)

Sometimes

Rarely/never

Only at night

$0.99 \quad 1.03$

Husband supports wife in conflict

Never (ref)

Sometimes

Always

Spousal age difference

2 yrs. (ref)

3-5 yrs.

$\geq 6$ yrs.

Spousal educational difference

Husband more educated (ref)

Spouses similarly educated

Wife more educated

$\begin{array}{ll}1.00 & 1.00 \\ 0.99 & 0.46^{*} \\ 0.92 & 0.49^{* * *} \\ 0.97 & 0.89^{* * *} \\ & \\ 1.00 & 1.00 \\ 1.72^{* *} & 1.34 \\ 0.96 & 1.00 \\ & \\ 1.04 & 1.16^{* * *} \\ 0.96 \dagger & 0.94 \dagger\end{array}$

\section{Household}

Family type

Nuclear (ref)

Extended

Religion

Hindu (ref)

Muslim

Standard of living

Low (ref)

Medium

High

$\begin{array}{ll}1.00 & 1.00 \\ 1.37 & 1.25 \\ 0.68^{*} & 0.44^{* *} \\ & \\ 1.00 & 1.00 \\ 1.21 & 1.32 \\ 1.24 & 1.53 \\ 0.77 & 1.33 \\ & \\ 1.00 & 1.00 \\ 1.83^{* *} & 1.48 \\ 0.69 * * * & 0.49^{* * *} \\ & \\ 1.00 & 1.00 \\ 1.01 & 1.23 \\ 1.06 & 0.98 \\ & \\ 1.00 & 1.00 \\ 0.86 & 1.25 \\ 1.26 & 1.15\end{array}$

\section{Context}

State

$\begin{array}{lll}\text { Gujarat (ref) } & 1.00 & 1.00 \\ \text { West Bengal } & 2.44^{* * *} & 0.77\end{array}$

${ }^{*} p \leq .05 .{ }^{* *} p \leq .01 .{ }^{* * *} p \leq .001 .+p \leq .10$. Notes: The comparison category for each analysis is no unwanted sex. The analysis presented above is based on a sample of 1,531 women (133 cases were removed because of missing information on some of the independent variables). ref=reference group. The standard of living index was based on housing materials and ownership of agricultural land, livestock and household durables (pressure cooker, electric fan, bicycle, radio, sewing machine, telephone, refrigerator, television, motorcycle, and car or tractor). Scores assigned for owning these assets ranged from 1 to 4 ; index score ranged from 0 to 34 . Scores of $0-4$ were classified as low, 5-14 as medium and $\geq 15$ as high. 
$12-44 \%$ of young women reported experiencing unwanted sex within marriage. The proportions observed in our study are higher than levels of forced sex reported in previous surveys of young women, ${ }^{6,30}$ but comparable with levels of coerced sex reported in surveys of men ${ }^{31}$ in India.

That coerced sex is experienced in many instances without physical abuse, that it is not always labeled as coerced by the young women and that the same frequency of occurrences can be perceived as both frequent and rare speaks to the urgency of broadening the range of questions used to assess sexual coercion in quantitative surveys. If given the opportunity to do so, a woman who would deny having experienced forced sex might say that she had had sex with her husband to prevent an argument or punishment.

The correlates of unwanted sexual experience vary somewhat by the degree of unwanted sexual experience. Although certain factors are associated with both occasional and frequent unwanted sex, other factors are correlated with one or the other. Recently married young women are more vulnerable to frequent coerced sex than first-time mothers or mothers-to-be. These results, which are similar to findings from studies conducted in India and elsewhere, suggest that forced sexual experiences are common early in marriage. ${ }^{24,26-28,32-36}$ Also, the protective influence of pregnancy and motherhood that we observed fit with findings from other studies that in some settings violence during pregnancy is less accepted, even when violence against women is common. ${ }^{7}$ Variables related to the nature of the relationship between husband and wife-familiarity with the husband at the time of marriage and having a supportive couple relationship-also reduce the risk of unwanted sex.

The finding that women who believe men are justified in beating their wives under certain circumstances are at greater risk of frequent unwanted sex supports other evidence that traditional gender norms that equate masculinity with toughness and dominance, and femininity with submissiveness, may place married young women at greater risk of unwanted sexual experiences. ${ }^{1,14}$ Women who experience frequent unwanted sex may have internalized norms that justify such abuse.

Our findings underline the importance of schooling: The risk of frequent unwanted sex declines as years of schooling increase. Schooling has been found to be protective against domestic violence in some settings, including India. ${ }^{37}$ Education may give a young woman more resources-for example, the ability to interact with the world outside her extended family-that confer more equal relations with her husband and better equip her to negotiate sex. The finding that a lower standard of living is a risk factor for unwanted sex corroborates the findings of other studies that household economic pressure is directly related to sexual coercion. ${ }^{38}$ Finally, religion is found to be correlated with unwanted sex.

\section{Limitations}

The study had a number of limitations. First, as discussed in the data section, we had a nonresponse rate of $26 \%$. Data on young women's age and life stage available from the household listing indicate that there were no significant differences in the age distribution of those who were interviewed and those who were not; however, it was primarily young women who were newly married or pregnant for the first time who were lost for interview rather than first-time mothers. Data on other background characteristics were not available for those who were not interviewed.

The analysis presented in this article was limited to a subsample of women who articulated their preference when they did not want sex. We acknowledge that many women who never told their husband no when sex was unwanted may also have experienced unwanted sex. Hence, we caution readers about the possible underestimation of the prevalence of unwanted sex because of this selection bias. The similarities found between the quantitative and qualitative data and the comparability of our findings with other studies suggest that selection bias might not have compromised the validity of our findings.

Also, we excluded about $7 \%$ of the study sample from the multivariate analysis because of missing information, mainly on husband's age and years of schooling. In addition, because it was important to keep the questionnaire to a reasonable length to allow gathering of quality data, we were not able to include a detailed module on intimate partner violence that would have allowed us to explore the different categories and nuances of sexual coercion and other forms of violence within marriage. Consequently, in the quantitative analysis, we did not distinguish between unwanted sex that happened as a result of physical force, threats of abandonment, fear of abuse and passive acceptance. However, our qualitative data helps us to tease out some of these variations.

Finally, given the cross-sectional nature of our study, it is not possible to establish the temporal order between unwanted sex and some of the covariates considered in the analysis. Although we considered several background variables that could have confounded the correlations in the multivariate analysis, it is possible that other unmeasured factors confound these associations.

\section{Conclusions}

Our findings suggest several programmatic considerations. The substantial levels of unwanted sex observed in this study, particularly among recently married young women, clearly indicate that sexual and reproductive health programs must recognize that many of their clients are having sex against their expressed will. Whether their goal is to assist women in protecting themselves from HIV infection or to provide women with contraception, such programs must incorporate education and counseling services to help prevent sexual coercion within marriage and address its adverse effects on sexual and reproductive health. Programmatic efforts to change the norms that give men the sense of entitlement to have sex with their wives whenever they desire and those that condone violence against women are also indicated.

The fact that a supportive couple relationship is protective against unwanted sex suggests the importance of ef- 
forts that target newly married couples, fostering communication, intimacy and an understanding of sexual rights. Similarly, it may help young women have more positive experiences if they are better equipped with information regarding sex and sexual pleasure, with an understanding of their right to be free from coercion, and with the skills and agency to articulate and achieve their desires.

Methodologically, several points are worth noting. Estimates of sexual coercion defined solely by forced sex variables are likely to underestimate the extent and intensity of coerced sex. Our findings that unwanted sex is experienced in many instances without physical abuse and may not be labeled as coerced by the young women themselves strongly indicate the need to broaden the range of questions used to assess sexual coercion in quantitative surveys. Without more nuanced data, the prevalence of sexual coercion will be underestimated and its nature and effects not fully understood. Further research to assess the effects of unwanted sex in marriage on sexual and reproductive health outcomes, as well as on how programs may best address and prevent sexual coercion within marriage, is urgently needed.

\section{REFERENCES}

1. Jejeebhoy SJ and Bott S, Non-consensual sexual experiences of young people in developing countries: an overview, in: Jejeebhoy SJ, Shah I and Thapa S, eds., Sex Without Consent: Young People in Developing Countries, London: Zed Books, 2006, pp. 3-45.

2. Ellsberg MC, Sexual violence against women and girls: recent findings from Latin America and the Caribbean, in: Jejeebhoy SJ, Shah I and Thapa S, eds., Sex Without Consent: Young People in Developing Countries, London: Zed Books, 2006, pp. 49-58.

3. Im-em W, Kanchanachitra C and Archavanitkul K, Sexual coercion among ever-partnered women in Thailand, in: Jejeebhoy SJ, Shah I and Thapa S, eds., Sex Without Consent: Young People in Developing Countries, London: Zed Books, 2006, pp. 74-85.

4. Santhya KG and Jejeebhoy SJ, Young women's experiences of forced sex within marriage: evidence from India, in: Jejeebhoy SJ, Shah I and Thapa S, eds., Sex Without Consent: Young People in Developing Countries, London: Zed Books, 2006, pp. 59-73.

5. Allen DR et al., Sexual health risks among young Thai women: implications for HIV/STD prevention and contraception, AIDS and Behavior, 2003, 7(1):9-21

6. Alexander M et al., Formation of Partnerships Among Young Women and Men in Pune District, Maharashtra, New Delhi: Population Council, 2006.

7. García-Moreno et al., WHO Multi-Country Study on Women's Health and Domestic Violence Against Women: Initial Results on Prevalence, Health Outcomes and Women's Responses, Geneva: World Health Organization (WHO), 2005.

8. Erulkar AS, The experience of sexual coercion among young people in Kenya, International Family Planning Perspectives, 2004, 30(4):182-189.

9. Koenig MA et al., Coerced first intercourse and reproductive health among adolescent women in Rakai, Uganda, International Family Planning Perspectives, 2004, 30(4):156-163.

10. Maharaj P and Munthree C, Coerced first sexual intercourse and selected reproductive health outcomes among young women in KwaZulu-Natal, South Africa, Journal of Biosocial Science, 2007, 39(2):231-244.

11. Cáceres CF, Marín BV and Hudes ES, Sexual coercion among youth and young adults in Lima, Peru, Journal of Adolescent Health, 2000, 27(5):361-367.
12. Hoffman S et al., HIV risk behaviors and the context of sexual coercion in young adults' sexual interactions: results from a diary study in rural South Africa, Sexually Transmitted Diseases, 2000, 33(1):52-58.

13. Kelly L, Surviving Sexual Violence, Minneapolis, MN, USA: University of Minnesota Press, 1988

14. Heise L, Ellsberg M and Gottemoeller M, Ending violence against women, Population Reports, 1999, Series L, No. 11.

15. Kirby D et al., An impact evaluation of project SNAPP: an AIDS and pregnancy prevention middle school program, AIDS Education and Prevention, 1997, 9(Suppl. 1):44-61.

16. Abma J, Driscoll A and Moore K, Young women's degree of control over first intercourse: an exploratory analysis, Family Planning Perspectives, 1998, 30(1):12-18.

17. Krug EG et al., World Report on Violence and Health, Geneva: WHO, 2002.

18. Yimin C et al., Case-controlled study on relevant factors of adolescent sexual coercion in China, Contraception, 2001, 64(2):77-80.

19. Rickert VI et al., Rates and risk factors of sexual violence among an ethnically diverse sample of adolescents, Archives of Pediatrics $\&$ Adolescent Medicine, 2004, 158(12):1132-1139.

20. Manopaiboon C et al., Sexual coercion among adolescents in northern Thailand: prevalence and associated factors, Southeast Asian Journal of Tropical Medicine and Public Health, 2003, 34(2):447-457.

21. Registrar General, India, Census of India, Marriage Tables, New Delhi: Government of India, 2001, C Series.

22. Jejeebhoy SJ and Sebastian MP, Young people's sexual and reproductive health, in: Jejeebhoy SJ, ed., Looking Back, Looking Forward: A Profile of Sexual and Reproductive Health in India, New Delhi: Rawat Publications, 2004, pp. 138-168.

23. Ouattara M, Sen P and Thomson M, Forced marriage, forced sex: the perils of childhood for girls, Gender and Development, 1998, 6(3):27-33.

24. Sodhi $G$ and Verma M, Sexual coercion among unmarried adolescents of an urban slum in India, in: Bott S et al., eds., Towards Adulthood: Exploring the Sexual and Reproductive Health of Adolescents in South Asia, Geneva: WHO, 2003, pp. 91-94.

25. Khan ME et al., Sexual violence within marriage, Seminar, 1996, No. 447 , pp. 32-35.

26. Sharma V, Sujay R and Sharma A, Can married women say no to sex? Repercussions of the denial of the sexual act, Journal of Family Welfare, 1998, 44(1):1-8.

27. Joshi A et al., Experiences and perceptions of marital sexual relationships among rural women in Gujarat, India, Asia-Pacific Population Journal, 2001, 16(2):177-194.

28. Maitra S and Schensul SL, The evolution of marital relationship and sexual risk in an urban slum community in Mumbai, in: Verma RK et al., eds., Sexuality in the Time of AIDS: Contemporary Perspectives from Communities in India, New Delhi: Sage Publications, 2004, pp. 129-155.

29. Registrar General, India, Census of India, Provisional Population Totals, New Delhi: Government of India, 2001, Series I, Paper 1.

30. Visaria L, Violence against women: a field study, Economic and Political Weekly, 2000, 35(20):1742-1751.

31. Martin SL et al., Sexual behaviors and reproductive health outcomes: associations with wife abuse in India, Journal of the American Medical Association, 1999, 282(20):1967-1972.

32. George A and Jaswal S, Understanding sexuality: an ethnographic study of poor women in Bombay, India, Women and AIDS Research Program Report Series, Washington, DC: International Center for Research on Women, 1995, No. 12.

33. Ellsberg M et al., Candies in hell: women's experiences of violence in Nicaragua, Social Science \& Medicine, 2000, 51(11):1595-1610.

34. George A, Embodying identity through heterosexual sexualitynewly married adolescent women in India, Culture, Health and Sexuality, 2002, 4(2):207-222. 
35. Khan ME, Townsend JW and D'Costa S, Behind closed doors: a qualitative study on sexual behaviour of married women in Bangladesh, Culture, Health \& Sexuality, 2002, 4(2):237-256.

36. Puri M, Cleland J and Matthews Z, Extent of sexual coercion among young female migrant workers and their sexual health problems in Nepal, paper presented at the annual meeting of the Population Association of America, Minneapolis, MN, USA, Apr. 1-3, 2003.

37. Kishor S and Johnson K, Profiling Domestic Violence: A Multi-Country Study, Calverton, MD, USA: ORC Macro, 2004.

38. Koenig MA et al., Individual and contextual determinants of domestic violence in North India, American Journal of Public Health, 2006, 96(1):132-138.

\section{RESUMEN}

Contexto: Aunque hay un creciente conjunto de investigaciones que examinan el tema de las relaciones sexuales no consensuales entre adolescentes, pocos estudios han abordado las relaciones sexuales en condiciones de coerción dentro del matrimonio en entornos donde el matrimonio temprano es común, y pocos han explorado las relaciones sexuales que pueden no ser percibidas como forzadas pero que no son deseadas.

Métodos: Un estudio transversal, que utilizó tanto investigación mediante encuestas como entrevistas en profundidad, se condujo entre mujeres jóvenes casadas en Gujarat y Bengala Occidental, India. La investigación utilizó datos descriptivos y regresión logística multinomial para identificar la prevalencia y los factores de riesgo para las relaciones sexuales no deseadas, tanto ocasionales como frecuentes. Para examinar el contexto en el que ocurren las relaciones sexuales no deseadas, se llevó a cabo el análisis de datos cualitativos.

Resultados: Doce por ciento de las mujeres jóvenes casadas experimentaron frecuentemente relaciones sexuales no deseadas; $32 \%$ las experimentaron ocasionalmente. El riesgo de experimentar relaciones sexuales no deseadas fue menor entre mujeres que conocían a sus esposos en el momento del matrimonio, que recibían apoyo con regularidad de sus esposos en conflictos con otros miembros de sus familias o que vivían en hogares de condiciones económicas más favorables. Las relaciones sexuales no deseadas frecuentes se asociaron con el hecho de no haber tenido todavía un hijo o haber quedado embarazadas, con un menor nivel de educación y con la aceptación de normas que justifican que se golpee a las esposas.

Conclusión: Para las mujeres jóvenes casadas, las relaciones sexuales no siempre son consensuales o deseadas. Se requiere más investigación para determinar los efectos de las relaciones sexuales no deseadas en la salud sexual y reproductiva, así como para ayudar a que los programas desarrollen las mejores estrategias para enfrentar las relaciones sexuales en condiciones de coerción dentro del matrimonio.

\section{RÉSUMÉ}

Contexte: Malgré le volume grandissant de la recherche relative à la question des rapports sexuels non consensuels dans la population adolescente, peu d'études se sont penchées sur les rapports imposés au sein du mariage dans les contextes où le mariage précoce est courant, ou sur les rapports non désirés même s'ils ne sont pas perçus comme forcés.

Méthodes: Une étude transversale, basée sur les données d'enquêtes et d'entrevues en profondeur, a été menée parmi les jeunes femmes mariées de Gujarat et de West Bengal, en Inde. Les données descriptives et la régression logistique multinomiale ont servi à déterminer la prévalence et les facteurs de risque de rapports sexuels non désirés occasionnels ou fréquents. Les données qualitatives ont servi à l'examen du contexte des rapports sexuels non désirés.

Resultats: Douze pour cent des jeunes femmes mariées subissaient fréquemment des rapports sexuels non désirés; $32 \%$ en subissaient occasionnellement. Le risque de tels rapports était moindre parmi les femmes qui connaissaient leur époux au moment du mariage, qui bénéficiaient régulièrement du soutien de leur époux dans les situations de conflit avec d'autres membres de la famille ou qui vivaient dans les ménages économiquement mieux lotis. Les rapports sexuels non désirés fréquents se sont révélés associés à l'absence de maternité ou d'une première grossesse, aux niveaux d'instruction inférieurs et à l'approbation des normes qui justifient la violence conjugale à l'encontre des femmes. Conclusion: Pour les jeunes femmes mariées, les rapports sexuels ne sont pas toujours consensuels ou désirés. Il est nécessaire de procéder à une recherche approfondie pour déterminer les effets des rapports sexuels non désirés sur les issues de santé sexuelle et génésique et pour aider les programmes à définir les meilleures stratégies d'approche de la contrainte sexuelle au sein du mariage.

\section{Acknowledgments}

Earlier versions of this paper were presented at the XXV International Population Conference, Tours, France, July 18-23, 2005, and the annual meeting of the Population Association of America, Los Angeles, CA, USA, March 30-April 1, 2006. The authors thank Shireen Jejeebhoy, Kelly Hallman and Judith Bruce for valuable comments on early drafts of this paper, and Saswata Ghosh and Ajay Singh for their help in data analysis. This study was supported by the Department for International Development, the Bill and Melinda Gates Foundation, the John D. and Catherine T. MacArthur Foundation, the Andrew W. Mellon Foundation, the Summit Foundation and the Community Foundation for the National Capital Region.

Author contact: kgsanthya@popcouncil.org 